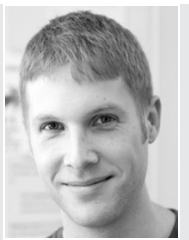

Stefan Heyne
PhD student, Department of Energy and Environment, Chalmers University of Technology, Göteborg. Sweden

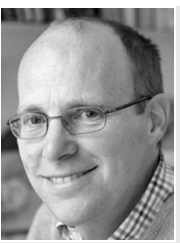

Simon Harvey

Professor, Department of Energy and Environment, Chalmers University of Technology, Göteborg Sweden

\title{
Methane from biomass: process-integration aspects
}

\section{S. Heyne and S. Harvey}

The production of synthetic natural gas (SNG) via biomass gasification constitutes a promising option for biofuel manufacture due to its high conversion efficiency and diversity of end-use opportunities in different sectors. This paper presents a critical review of possible feedstock conversion paths from biomass to SNG via gasification. Similarities with research and development issues for coal gasification projects for SNG production are identified and the state of the art for the bottleneck stages of the conversion is discussed. The need for tools to improve process efficiency is clearly shown; the pinch methodology is a powerful tool for process integration and is of particular interest in this regard. Biofuel production processes often deliver multiple products and services such as heat, electricity and other by-products and are often referred to as polygeneration or biorefinery concepts. To take into account the multiple possible products and services resulting from SNG production, it is necessary to carefully define appropriate process performance indicators. For a sound assessment of the future potential of biomass-based SNG production, an evaluation of the most promising process alternatives against a background of possible future energy market scenarios is necessary.

\section{INTRODUCTION}

The emission of anthropogenic greenhouse gases (GHGs) has increased dramatically over the last century and emissions reduction is a major challenge in both the industrialised and developing world. Achieving economic growth without a rapid increase in emissions is of central importance. Biomass-based energy is one of the options pursued to reduce fossil carbon dioxide emissions. The share of renewables in the primary energy supply mix in the European Union is 6.92\% (in 2007), with biomass accounting for two-thirds of that share. ${ }^{1}$ Worldwide, biomass is the most important source of renewable energy today, accounting for about 9\% of total primary energy use. ${ }^{2}$ However, only about $10 \%$ of this biomass is used on an industrial scale for the production of electricity or fuels. The future use of bioenergy is expected to increase significantly, with some scenarios predicting usage at the level of today's oil consumption in $2050 .^{2}$ The use of biomass for heat and power generation as well as the production of biomass-based transportation fuels is therefore a topic of imminent importance. A holistic and global approach is needed for a sound development of the bioenergy market. Currently available and commercial fuel production options from biomass (the so-called first-generation biofuels) are criticised because the growth of energy crops competes directly with food production., Furthermore, the efficiencies of current production routes are often unsatisfactory as only a relatively low fraction of the energy content of the incoming biomass feedstock is converted to motor vehicle fuel.

The International Energy Agency has proposed the production of second-generation biofuels - that is, transportation fuels based on lignocellulosic feedstocks that are not yet commercially available - as one of the 17 roadmaps to a sustainable global energy scenario. ${ }^{2}$ A key technology for the production of these fuels is gasification. Based on the syngas resulting from the gasification stage, there are numerous options for downstream fuel production, for example methanol, Fischer-Tropsch (FT) diesel, hydrogen, dimethyl ether (DME) and synthetic natural gas (SNG), sometimes also referred to as biomethane or substitute natural gas. Several studies have compared the overall conversion efficiencies of the different process chains, their corresponding environmental impacts and different policy strategies. ${ }^{3,5-8}$

A recent study ${ }^{5}$ compared the efficiencies of FT diesel, methanol and SNG production based on an energy input of biomass corresponding to $50 \mathrm{MW}$ and an indirect gasification technology. The research showed that SNG achieves the highest conversion efficiency based on biofuel yield when the processes are designed for maximum fuel yield. The study also stated that possible process by-products (such as electricity or heat) present interesting options for rendering the process more flexible as several services are delivered. These polygeneration schemes (in which a number of different products and services are produced) are of particular interest for plants of small to medium size - that is, up to $100 \mathrm{MW}$ biomass input. ${ }^{5}$ Economies of scale are not really applicable to these plant sizes, so it is advantageous to be able to vary production routes for different products - that is, some biofuel and electricity, depending on market conditions.

Polygeneration plants that convert biomass feedstock are often also called biorefineries. The optimum choice of processes and process design depends on a variety of factors such as fuel supply options, energy policy, subsidies, transportation infrastructure and market accessibility for the produced biofuel. A general consensus is that there is no 'golden path' but that contributions from a number of technologies and 
production routes will be needed to achieve substantial costeffective market growth of biomass-based fuels.

A recent well-to-wheel study focusing on the automotive transportation sector in a European context also states that solution of the GHG emission problem should not consist of a single pathway. ${ }^{6}$ The study presents an analysis of costs and carbon dioxide emissions for different fuel production pathways and powertrain combinations. Cars fuelled with gas originating from biomass fermentation have the highest potential for GHG emissions reduction: 167\% compared with a business-as-usual baseline case where the whole road fuel demand is satisfied with the conventional fossil fuel mix forecast for 2010-2020. A reduction of more than 100\% is achieved in the case of biogas because a GHG emission credit is given to the feedstock treatment (mainly wet manure in the study ${ }^{6}$ ), which drastically decreases methane $\left(\mathrm{CH}_{4}\right)$ emissions that would occur if the feedstock were left untreated releasing methane to the atmosphere. It, of course, can be argued whether this kind of argument holds in reality. Nevertheless, even though this high reduction can be achieved at low cost, the overall potential of biogas for GHG emissions reduction is restricted by its limited availability and distribution and refilling infrastructure. Synthetic fuels derived from wood (based on gasification (DME, FT diesel) or fermentation (ethanol)) also have high GHG emissions reduction potential - 92\%, 91\% and 75\% compared with the baseline case, respectively. SNG from gasified wood feedstock was not considered in the well-to-wheel study ${ }^{6}$ but its potential can be expected to lie in between that of biogas and synthetic fuels from wood gasification, taking into account the higher conversion efficiency for SNG production compared with FT diesel. ${ }^{5}$

Gas-driven powertrain efficiency in general is currently situated at a level between that of gasoline and diesel powertrains, but in the future they are expected to reach the efficiency level of diesel powertrains, even outperforming them in hybrid powertrain set-ups. ${ }^{6}$

The positive environmental effects of SNG as vehicle fuel have also been demonstrated by a life-cycle impact assessment comparing fossil fuels and SNG for car use. ${ }^{8}$ The study also investigated the use of SNG for heating purposes, but concluded that the better option for the use of SNG is in the transportation sector. This conclusion must, however, be interpreted with caution since combined heat and power (CHP) production was not taken into account when identifying alternative options for delivering heating services.

This paper presents an overview of SNG production via biomass gasification. The potential of SNG as a biofuel is illustrated, followed by an investigation of the state of the art in different conversion steps. Finally, critical aspects of SNG production (from the authors' point of view), namely process integration and process performance indicators, are discussed and a concluding critical review of current research needs is presented.

\section{POTENTIAL OF SNG IN A BIOFUEL CONTEXT}

The whole range of so-called second-generation biofuels is currently being investigated at length by researchers. Some of the potential advantages of SNG over other biofuels include the following. (a) Infrastructure is in place (SNG can be fed into the existing natural gas grid).

(b) There is a high level of experience in gas storage gained from natural gas.

(c) It is a clean-burning fuel with many off-the-shelf technologies achieving ultra-low emissions.

(d) There is a large range of ready-to-use applications for transportation, the energy sector and industry.

(e) SNG could constitute a positive vector for transition to a hydrogen economy since the natural gas grid could be used to phase in hydrogen in the future. ${ }^{9}$

Of course, SNG cannot be used to replace all current natural gas usage. To give an idea of the potential in European countries, the amount of biomass energy available for SNG production per year in southern Sweden has been estimated to be $34 \mathrm{TWh}^{10}$ (This estimate is limited to the south of Sweden since the natural gas grid is well developed there, in contrast to the northern parts of the country where market options are limited by restricted distribution alternatives for SNG.) This is a significant amount considering that the total primary energy production from biomass in Sweden for 2006 was 104 TWh. ${ }^{1}$ In Germany, the potential is about $280 \mathrm{TWh} / \mathrm{year}$, theoretically making it possible for biomass to cover around 7\% of the primary energy consumption for the year $2005 .{ }^{11}$

\section{TECHNOLOGY}

The key process step for the production of SNG from biomass is the gasification unit. In the early nineteenth century, coal gasification was used for the production of so-called town gas for street lamps. Later, gasification was used during World War II to produce liquid fuels from coal, and the process underwent a revival during the oil crises of the 1970s and 1980s.

Fundamental research and equipment development was carried out during these periods and has provided an important knowledge database for gasification. ${ }^{12}$ Prominent developments of gasification units from this period include the British GasLurgi (BGL) fixed-bed gasifier, the Kellogg-Rust-Westinghouse (KRW) fluidised bed gasifier and the Reinbraun AG hydrogasifier. However, dramatic changes in world energy markets rendered coal gasification economically unfeasible and research activities rapidly decreased alongside declining interest from industry. One notable exception, however, is the Great Plains Synfuel Plant $;{ }^{13}$ it has been in constant operation since 1984, producing up to $2 \mathrm{GW}$ of grid-quality SNG from coal. The plant has undergone many modifications and improvements, for example diversifying the by-product range to maintain economic viability, thereby providing an important knowledge database on SNG production from coal.

In a paper published in $1987,{ }^{14}$ SNG from coal was predicted to be a 'potential pipeline-quality gas supply option for the post 2000 frame'. Indeed, several recent projects are aiming at SNG production via coal gasification, for example a standard industrial-scale coal-to-SNG process planned for start-up in $2010^{15}$ and a coal-to-SNG process with co-production of biofuel and electricity based on hydrogasification. ${ }^{16}$ Over recent decades, biomass gasification has been investigated in a number of projects aiming at carbon dioxide emissions reduction within the energy sector. ${ }^{17-31}$ Research needs mentioned in reviews on coal gasification for SNG production resemble present requirements in biomass gasification - the need for large-scale 


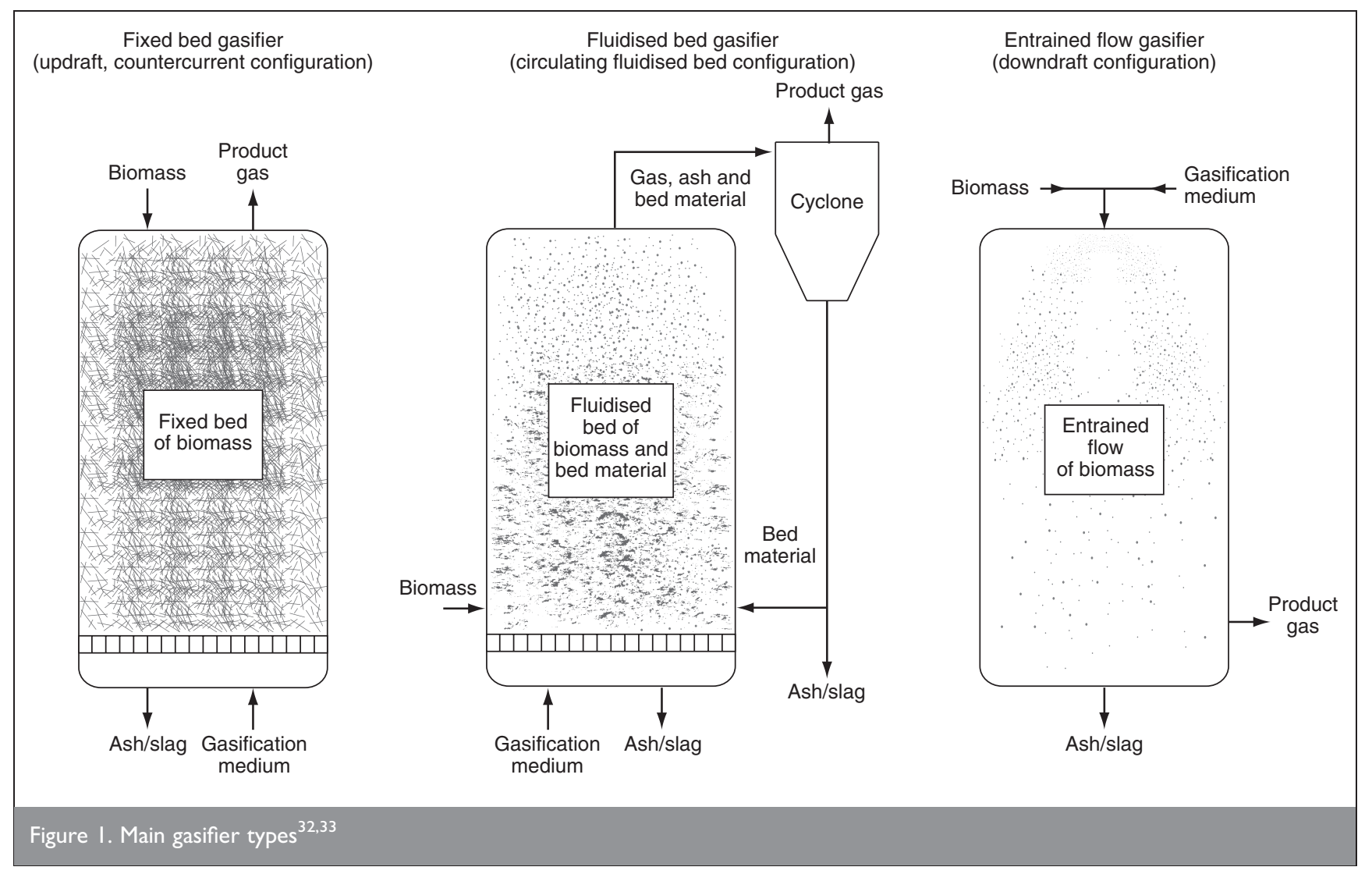

operational and performance data, integrated performance evaluations of advanced gasification technologies, ${ }^{14}$ and so on.

The choice of gasifier used and the choice of gasification medium depend to a large extent on both the feedstock properties and the potential application of the resulting product gas/syngas. Figure $1^{32,33}$ shows a schematic illustration of the three most common types of gasifier and their main characteristics are summarised in Table $1 .{ }^{11,32,33}$ The ranges given in Table 1 are only indicative because, in practice, gasifier characteristics depend on the kind of feedstock that is converted. For fluidised bed gasification, for example, the maximum operating temperature is limited by the melting temperature of the feedstock's ash content, since higher temperatures would cause sintering of the bed.

An overview of most current biomass gasification projects is available in the literature. ${ }^{30}$ They include the following.

(a) In Güssing (Austria) an $8 \mathrm{MW}$ fast internal circulating fluidised bed (FICFB) gasification demonstration plant has been in operation since $2001 .^{17,18}$

(b) In Värnamo (Sweden) a demonstration power plant for biofuel-fired CHP generation delivering $6 \mathrm{MW}$ of electricity and 9 MW of thermal energy to a district heating network from a biomass input of 18 MW was in operation from 1996 to $2000 .{ }^{19,20}$ The plant was thereafter modified for testing as a unit for the production of high-quality syngas for downstream conversion to transportation fuels or other higher-value chemicals. ${ }^{34}$

(c) The Energy Research Centre of the Netherlands (ECN $)^{21-23}$ has developed a gasification technology that has been demonstrated at laboratory scale and is currently the object of a $10 \mathrm{MW}$ input gasification demonstration plant.

(d) At Skive (Denmark) and Andhra Pradesh (India) biomass gasification demonstration plants for CHP production based on the same technology - bubbling fluidised bed gasification - are in operation. ${ }^{24-26}$

(e) The Technical University of Denmark (DTU) demonstrated the feasibility of two-stage gasification technology in a lab-scale demonstration plant. ${ }^{27}$

(f) In Freiberg (Germany) a commercial plant based on a twostage gasification technology producing $18000 \mathrm{~m}^{3}$ of FT diesel moved into start-up phase in April 2008. ${ }^{31,35}$

Specifically aiming at the production of SNG are the project at Güssing (where feasibility has been demonstrated with a slip stream of the produced syngas ${ }^{36}$ ) and the ECN gasification

\begin{tabular}{|c|c|c|c|}
\hline & Fixed bed & Fluidised bed & Entrained bed \\
\hline Input particle size: $\mathrm{mm}$ & $10-300$ & $<50$ & $<0.1$ \\
\hline Outlet gas temperature: ${ }^{\circ} \mathrm{C}$ & $400-1000$ & $700-1200$ & $1200-1500$ \\
\hline Operating pressure & & From atmospheric pressure (I bar) to $\sim 25 \mathrm{bar}$ & \\
\hline Gasification medium & & Air, steam, oxygen, flue gas, syngas & \\
\hline Plant size: $\mathrm{MW}_{\text {th }}$ input & $<50$ & $10-100$ & $100-1000$ \\
\hline
\end{tabular}




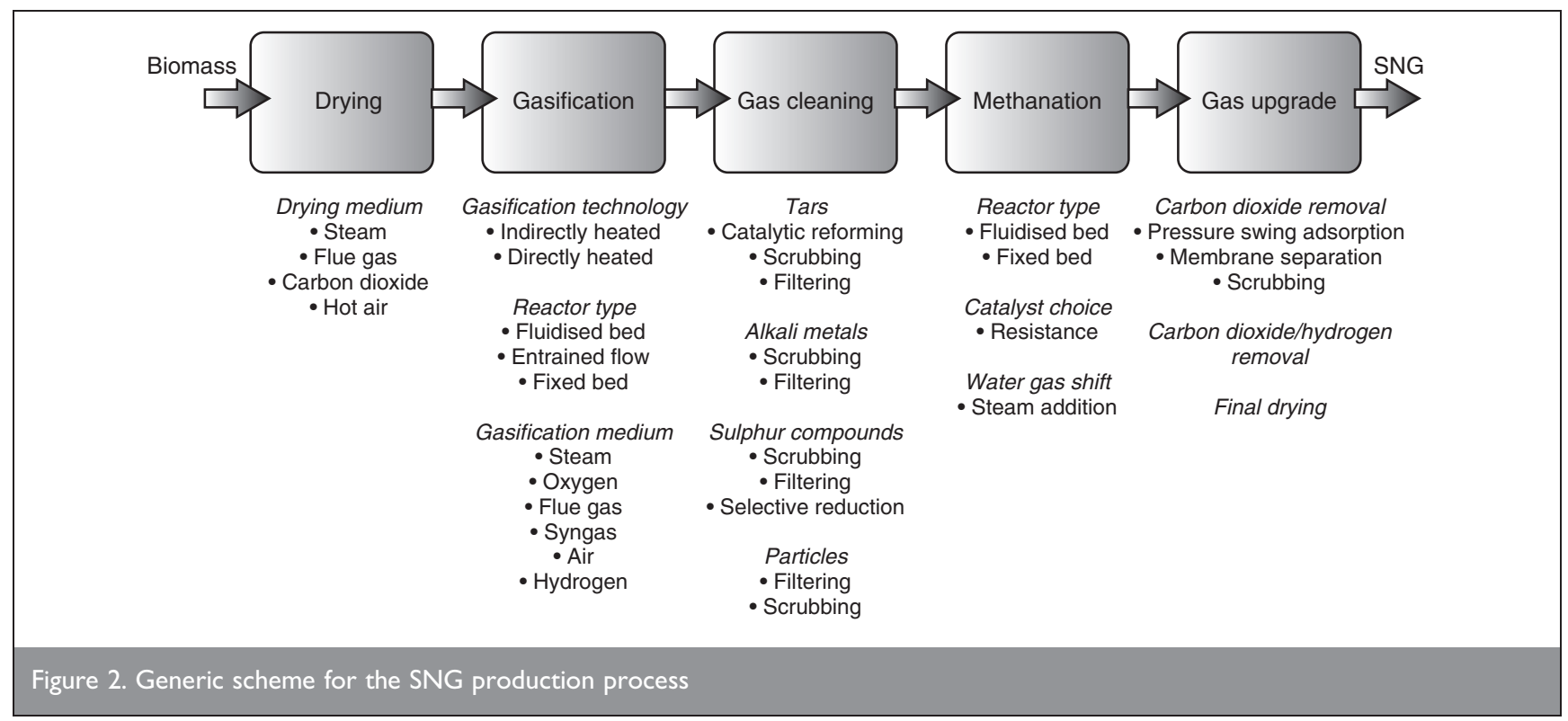

project. ${ }^{21-23}$ Feedstock conversion efficiency estimates for the production of SNG range from 60\% to 70\% and even higher for large-scale applications. ${ }^{5,21,22}$

\section{SNG FROM BIOMASS: PROCESS STEPS}

A generic scheme for the production of SNG is shown in Figure 2.

\section{I. Drying}

This first step is crucial to increase the gasification efficiency. The most common technologies are steam drying, hot air drying and flue gas drying. ${ }^{37-40}$ A comparison of flue gas, steam and hot air drying ${ }^{37}$ shows that flue gas drying is characterised by low exergy losses and lower emissions of organic substances. The water content of woody biomass is usually about $50 \mathrm{wt} \%$. It should be decreased substantially prior to gasification in order to avoid an increased high-temperature energy input into the gasification unit. For an integrated gasification combined cycle (IGCC) process it has been shown that reducing the water content of the wood feedstock from 40 to $15 \%$ results in an improvement in electrical efficiency of $2 \cdot 5 \% .{ }^{37}$ When considering gasification for the production of SNG, the methane yield in the gasification step is important. This yield is influenced by the water content of the biomass feedstock and a water content of $20-30 \%$ is considered optimal for SNG production. $^{11}$

\subsection{Gasification}

Depending on the gasification technology, gasification medium and operating conditions, the composition of the resulting product gas can vary significantly. Table $2^{41-43}$ shows typical gas compositions for gasification at atmospheric pressure in fluidised bed reactors. For gasification with air, the nitrogen content in the product gas is high. The variations in product gas composition for steam gasification from different literature sources can be mainly attributed to differences in feedstock composition and operating conditions. This emphasises the importance of taking feedstock properties into account when choosing a gasifier design. Since nitrogen is difficult to separate, it is preferable to use steam or oxygen as the gasification medium because the resulting SNG has a higher energy content and only contains small amounts of nitrogen that originate from the fuel itself and from air leakage into the system.

\subsection{Gas cleaning}

Besides the main components of carbon monoxide, hydrogen, carbon dioxide, methane and nitrogen, several trace substances are also present in the product gas. These include particulates (entrained ash and bed material), sulphur compounds (hydrogen sulphide, carbonyl sulphide), alkali compounds (mainly chlorine compounds) and tars or higher hydrocarbons that are prone to condensation at temperatures around $300-350^{\circ} \mathrm{C}^{44,45}$ and can

\begin{tabular}{|c|c|c|c|c|}
\hline & \multicolumn{4}{|c|}{ Gasification medium } \\
\hline & Steam $^{41,42}$ & Steam $^{43}$ & Steam-oxygen mixture ${ }^{43}$ & $\mathrm{Air}^{43}$ \\
\hline Carbon monoxide: vol.\% & $20-30$ & $17-32$ & $42 \cdot 5-52 \cdot 0$ & $9 \cdot 9-22 \cdot 4$ \\
\hline Hydrogen: vol.\% & $30-40$ & $38-56$ & $|3 \cdot 8-3| \cdot 7$ & $5 \cdot 0-16 \cdot 3$ \\
\hline Methane: vol.\% & $8-12$ & $7-12$ & $6 \cdot 0-7 \cdot 5$ & $2 \cdot 2-6 \cdot 2$ \\
\hline Carbon dioxide: vol.\% & $15-25$ & $13-17$ & $14 \cdot 4-36 \cdot 3$ & $9.0-19.4$ \\
\hline Nitrogen: vol.\% & $1-5$ & 0 & 0 & $4|\cdot 6-6| \cdot 6$ \\
\hline Carbon compounds: vol.\% & 3 & 2 & $2 \cdot 5-3 \cdot 6$ & $0 \cdot 2-3 \cdot 3$ \\
\hline
\end{tabular}


therefore foul pipes and equipment. Removal of these substances is of particular importance in SNG production since the methanation reaction uses catalysts that are highly sensitive to impurities in the gas. A number of different gas cleaning technologies exist.

(a) Particulates can be removed using standard technologies such as cyclones, filters and separators. Particle separation also reduces the tar content of the syngas, the extent of tar removal depending on the particle separation technology used. $^{46}$

(b) Tar removal or conversion can be achieved by physical washing using organic solvents, ${ }^{47}$ wet electronic separators or catalytic reformers. ${ }^{25}$ Physical washing techniques require cooling of the syngas, which results in restricted flexibility for heat recovery options. Catalytic reforming of tars has the advantage of keeping the carbon contained in the tars available for further conversion to fuel. Another option to reduce the tar content of the syngas is the use of catalytic bed material in the gasification reactor. Olivine sand has been shown to effectively reduce the tar content in syngas from steam gasification. ${ }^{48}$ The use of catalytic bed material has already been demonstrated in coal gasification projects for SNG production, ${ }^{49}$ with the catalyst material promoting methane equilibrium (leading to increased methane content in the product gas) rather than influencing the tar formation process. Other tar conversion techniques such as plasma cracking are still at an early development stage. Han and Kim give a review of the different techniques. ${ }^{46}$

(c) Sulphur compounds, mainly hydrogen sulphide, must be removed from the syngas to the best possible extent since they can poison catalysts. The methanation catalyst is particularly prone to sulphur poisoning. Regenerative sorbents (so-called sulphur guards) can be used to reduce sulphur concentrations to the necessary limits, well below $1 \mathrm{ppm} .{ }^{50}$ Washing techniques (based on physical or chemical adsorption) can also be implemented, making sulphur recovery via a Claus process possible if economically viable. ${ }^{51}$

\subsection{Methanation}

Two options exist: a fixed or a fluidised bed reactor. Within the framework of the numerous coal gasification projects carried out in the 1980s, several processes for methanation were developed. Fixed bed processes operating adiabatically with a recycle flow to control temperature (e.g. the Hygas ${ }^{52}$ or Lurgi $^{53}$ process) usually operate in a temperature range of about 250$500^{\circ} \mathrm{C}$. Temperature limits are generally imposed by carbonyl formation at too low temperatures, carbon deposition on the active catalyst surface and catalyst decomposition and sintering at higher temperatures. The Haldor Topsøe Tremp process ${ }^{54}$ is an exception to this; the catalyst operated well during long-term tests in temperatures up to $700^{\circ} \mathrm{C}$. A fluidised bed methanation process (Comflux) that is operated isothermally with internal cooling has been developed by Thyssen. ${ }^{55}$ Fluidised bed reactors have some advantages considering the reduced tendency of catalyst deactivation by deposition of coal on the active surface. ${ }^{56}$ Due to its strong exothermicity, the methanation process represents an important source of heat that has to be considered when integrating the different sub-processes of SNG production.

\subsection{Gas upgrading}

Finally, the gas has to be adapted to the required specifications, for example natural gas grid quality. The main step in gas upgrading is the removal of carbon dioxide, which represents a substantial fraction of the gas after methanation. Carbon dioxide capture is currently being investigated for coal-based power generation and a common solution considered for large-scale applications is an amine-based scrubbing technique. ${ }^{57-63}$ Other available techniques for the separation of carbon dioxide are pressure swing adsorption or membranebased processes. The gas must be dried and traces of hydrogen and carbon dioxide must be removed in case the concentration exceeds the specifications for the envisaged application. A quality index for natural gas often referred to is the Wobbe index; it relates the heating value to the specific density of a gas. The European Association for the Streamlining of Energy Exchange (EASEE-gas) ${ }^{64}$ recommends natural gas quality specifications including, among others, ranges for the Wobbe index, relative density, water dew point and limits for sulphur, oxygen and carbon dioxide concentrations. The process steps for gas upgrade to the necessary specifications are mature technologies used, for example, in facilities for upgrading biogas from fermentation processes.

The pressure level at which the produced SNG is to be delivered is also an important parameter. Since high pressure is advantageous or even necessary for optimal operation of some of the process step options, pressure levels within the different sub-processes have to be chosen with care. Compression work and process equipment size are important parameters, influencing investment and running costs.

\section{PROCESS INTEGRATION}

The number of different process step alternatives makes it necessary to evaluate different design options. A sound process design is important to guarantee economic feasibility of the SNG production process. The temperature and pressure levels of the different steps have to be optimised from an overall efficiency perspective. This is a non-trivial task since changes in these parameters influence both process step performances (such as the conversion efficiency in a single process step, e.g. methanation) and utility consumption (e.g. steam need, compression work).

A technique that has proven to be particularly suitable for investigating heat integration options for industrial processes is pinch analysis. ${ }^{65,66}$ It is used to identify different heat sources and sinks within a process and allows identification of the potential for internal heat exchange and opportunities for improvement of the latter through changes in the process. External heating and cooling can be reduced, leading to a better process design. The pinch methodology has been successfully applied in the chemicals, petrochemicals, oil refining, pulp and paper, food and drink, and steel and metallurgy industry sectors, and savings in energy consumption of about 10-35\% can usually be identified. ${ }^{67}$ A study focusing on the pulp and paper industry identified steam saving potentials of $12-21 \%$ using pinch analysis. ${ }^{68}$

For the design of a SNG production process, Gassner and Marechal $^{69}$ proposed a thermo-economic modelling approach based on multi-objective optimisation and integrating the pinch 


\begin{tabular}{|c|c|c|}
\hline Performance indicator & Advantages & Disadvantages \\
\hline $\begin{array}{l}\text { Cold gas efficiency (fuel conversion } \\
\text { efficiency) }\end{array}$ & $\begin{array}{l}\text { - Easy to calculate } \\
\text { - Clear idea of fuel yield }\end{array}$ & $\begin{array}{l}\text { - Does not account for by-products } \\
\text { - No information about overall process } \\
\text { efficiency }\end{array}$ \\
\hline $\begin{array}{l}\text { Thermal/energetic efficiency (first } \\
\text { law efficiency) }\end{array}$ & $\begin{array}{l}\text { - Possible to account for by-products } \\
\text { - Relatively easy to calculate }\end{array}$ & $\begin{array}{l}\text { Detailed information about system } \\
\text { boundaries necessary } \\
\text { - Limited information about the overall process } \\
\text { efficiency }\end{array}$ \\
\hline $\begin{array}{l}\text { Exergetic efficiency (second law } \\
\text { efficiency) }\end{array}$ & $\begin{array}{l}\text { - Possible to account for by-products } \\
\text { - Information on overall process efficiency }\end{array}$ & $\begin{array}{l}\text { - Efficiency related to a reference state } \\
\text { (definition necessary) } \\
\text { - Detailed information on system boundaries } \\
\text { necessary }\end{array}$ \\
\hline
\end{tabular}

Table 3. Process performance indicators available for biofuel production processes and their advantages and drawbacks

methodology. Their study considered both indirectly heated steam-blown gasification at atmospheric pressure and pressurised directly heated oxygen-blown gasification, and revealed advantages in efficiency for the indirect technology. Economic evaluation of the process is, however, limited to fixed electricity import and export price levels. Based on this work, Gassner and Marechal proposed the use of electrolysis as an efficient way of increasing SNG yield. ${ }^{70}$ Since syngas from biomass inherently has too low a hydrogen concentration for the methanation reaction, the use of electrolysis to provide the lacking hydrogen increases the yield. The potential of electrolysis is even more evident when considering oxygen-blown gasification because some of the oxygen can be supplied by electrolysis of water. Hydrogen produced in the electrolyser is added to the syngas, thereby increasing the methane yield, while the oxygen resulting from electrolysis can be used in the gasification process. The electricity consumed for electrolysis can thus be considered to be stored in the produced SNG, thereby offering the possibility of storing green electricity in the form of SNG. However, Gassner and Marechal point out that the current market price for electricity (€88.9/MWh in their study) renders the implementation of electrolysis economically unfeasible. A simplified profitability analysis based on variations in gas price and electricity costs was carried out, but does not, however, represent the complex interactions and pricing mechanisms in energy markets.

\section{PROCESS PERFORMANCE INDICATORS}

As already mentioned, SNG is not the only possible product. Electricity and heat as well as possible other by-products of value (recovery of sulphur, co-production of another fuel such as FT diesel) must also be taken into consideration when thinking about process design. In order to evaluate an SNG production process in comparison with alternative biofuel production routes it is important to define suitable generic performance indicators.

Table 3 gives an overview of the three most common performance indicators used for the evaluation of biofuel production processes and their characteristics. Cold gas efficiency only considers the calorific value of the biofuel output in relation to the biomass energy input. Thermal efficiency considers the energy content of the input and products of the process, whereas the exergetic efficiency compares the input and output based on the potential production of mechanical work according to the second law of thermodynamics. For both thermal and exergetic efficiency, system boundaries have to be clearly defined.

It is important to note that these three indicators are not directly comparable: a process with high cold gas efficiency is not necessarily a well-designed process considering the overall thermal or exergetic efficiency. Such performance indicators can obviously be defined for almost any conversion process. However, for biofuel production processes it is particularly important to clearly define system boundaries so as to account for relevant material and energy service by-products. This is necessary to enable a fair evaluation of different process alternatives and the use of performance indicators as a tool in the decision-making process. In order to provide useful practical guidance when selecting a production process, all efficiencies have to be interpreted while also taking other aspects (e.g. economics) into account.

An economic evaluation of the process needs to account for uncertainties regarding future development of fuel and electricity prices, as well as costs related to energy and environmental policy instruments (e.g. carbon dioxide emissions costs). Different future energy scenarios will favour different process designs since it might, for example, be more favourable to maximise SNG yield or to increase the co-generation of electricity depending on the corresponding market values of the different products and services supplied.

\section{CRITICAL REVIEW OF RESEARCH NEEDS}

For industrial-scale production of SNG, the development of process schemes aiming at high efficiency is necessary. Technically, most of the problems related to the production process are solved. However, for some of the process steps, industrial-scale and guaranteed operation have not yet been achieved. In particular, problems with tar are still a limiting factor despite many years of research and development. Techniques such as oil-scrubbing (which remove tar to acceptable levels) put large constraints on the heat recovery potential of the overall process, therefore reducing economic competitiveness. On the other hand, high-temperature tar-removal processes enabling good heat recovery (e.g. high-temperature ceramic filters) have so far only been 
demonstrated at laboratory/pilot scale and are not yet market-ready.

Even though several process integration studies have been conducted on SNG production, the biorefinery concept has not yet been fully applied. Most studies focus on SNG yield and do not consider overall efficiency within the framework of an economic market scenario. To further improve the economic viability of SNG production from biomass, several options exist for improving efficiency on a process integration level, including

(a) heat integration (minimising the amount of external heating and cooling by internal heat exchange)

(b) combined production of heat and power

(c) making use of possible by-products as well as synergy effects when extending existing combustion units with gasification for SNG production.

This latter concept was proposed by Thunman et al. ${ }^{71}$ The extension of fluidised bed boilers currently used for CHP production constitutes an interesting option for enhanced market introduction of biofuel, as lower costs and risks are involved. In this concept, the return leg of a fluidised bed boiler (where heat is usually recovered from the hot bed material with the help of a particle cooler for steam generation) can be retrofitted and a gasification unit installed instead. The gasification concept then resembles the FICFB concept but with gasification and combustion chambers switched. The steam/ electricity production of the power plant to be retrofitted is only slightly influenced: the reduced steam production rate due to the heat needed for gasification is compensated for by additional fuel supply to the combustion side in the form of non-gasified wood char. A detailed analysis of this concept that is, converting a power plant to a polygeneration site producing heat, electricity and SNG, is necessary before further conclusions can be drawn. Validation of models for the different steps used in process integration studies is an important aspect that is often treated insufficiently due to lack of data. Pilotscale data are necessary for building and refining models that can be used for reliable predictions of biorefinery processes.

Polygeneration concepts that deliver a number of useful byproducts require suitably defined process performance indicators in order to enable a fair evaluation and comparison of proposed process designs. A clear definition of the 'efficiency' of a process is indispensable. The performance indicators of different process alternatives then have to be analysed against the background of possible future energy market scenarios, as proposed and exemplified by Harvey and co-workers. ${ }^{72-74}$ The simple use of a fixed assumed future fuel price and carbon dioxide penalty - sometimes combined with sensitivity analysis - hardly reflects the complexity of energy markets and therefore does not provide sufficient information on which to base decision-making. The system aspects of price-building mechanisms and willingness-to-pay resulting from scenario tools have to be considered when attempting to define a suitable process design for SNG production with all its services and by-products. Energy market scenarios that represent energy market prices and carbon dioxide consequences of import/export of different energy streams (e.g. electric power and wood fuel) based on assumed fossil fuel prices and costs associated with policy instruments can be used to reflect different possible future energy market conditions. ${ }^{74}$ These scenarios can then be used to gain a better understanding of the long-term economic and climate change consequences of different process alternatives or process integration measures. ${ }^{72,73}$

\section{CONCLUSIONS}

Bioenergy is an interesting option for the reduction of GHG emissions. Among the different alternative uses of biomass, SNG as a fuel is a very promising pathway as it is a ready-touse fuel for a large number of efficient and clean energy applications in both transportation and industry. Different process design alternatives have to be investigated in detail and evaluated both economically and environmentally. Process integration tools such as pinch analysis will help to define optimum operation conditions and maximum internal energy recovery. In order to help policy makers take decisions, generic performance indicators for biofuel production must be developed to enable a fair comparison of the different alternative fuel production routes. In-depth economic evaluations against the background of future energy market scenarios are also necessary.

\section{ACKNOWLEDGEMENTS}

This project is financially supported by Göteborg Energi's Research Foundation and the Swedish Energy Agency. This paper follows a UK Energy Research Centre Sparks network event held at Roehampton University, 26 June 2008.

\section{REFERENCES}

1. OBSERV'ER. State of Renewable Energies in Europe - 2007 Edition. Observ'ER, Paris, 2007.

2. International Energy Agency. Energy Technology Perspectives 2008. International Energy Agency, Paris, 2008.

3. The Royal Society. Sustainable Biofuels: Prospects and Challenges. The Royal Society, London, 2008, policy document 01/08.

4. ZIEGLER J. The Right to Food. United Nations, New York, 2007, report No. A/62/289.

5. FÜRnsinn S. and Hofbauer H. Synthetische kraftstoffe aus biomasse: technik, entwicklungen, perspektiven. ChemieIngenieur-Technik, 2007, 79, No. 5, 579-590.

6. Edwards R., LarivÉ J.-F., Mahieu V. and Rouveirolles P. Well-to-wheels Analysis of Future Automotive Fuels and Powertrains in the European Context. European Commission Joint Research Centre, Brussels, 2007.

7. FAAIJ A. P. C. Bio-energy in Europe: changing technology choices. Energy Policy, 2006, 34, No. 3, 322-342.

8. FELDER R. and Dones R. Evaluation of ecological impacts of synthetic natural gas from wood used in current heating and car systems. Biomass and Bioenergy, 2007, 31, No. 6, 403-415.

9. Florisson 0., Alliat I. and Lowesmith B. The value of the existing natural gas system for hydrogen, the sustainable future energy carrier (progress obtained in the Naturalhyproject). Proceedings of the 23rd World Gas Conference, Amsterdam, 2006.

10. KARLSSON S. and MALM D. Förnybar Naturgas Förgasning av Biobränslen för Framställning av Metan eller Vätgas. Svenskt Gastekniskt Center, Malmö, 2005, report SGC156. 
11. Köppel W., Bajohr S., Graf F. and Reimert R. SNG from biomass - basics and challenges in process engineering. Gas und Wasserfach Gas Erdgas, 2007, 148, No. 2, 87-94.

12. COGARN. Summary of findings and research recommendations of Coal Gasification Advances Research Needs (Cogarn) studies. Energy, 1987, 12, No. 8-9, 623-903.

13. PANeK J. M. and Grasser J. Practical Experience Gained During the First Twenty Years of Operation of the Great Plains Gasification Plant and Implications for Future Projects. US Department of Energy, Washington, DC, 2007.

14. Woodcock K. E. and HiLl V. L. Coal gasification for SNG production. Energy, 1987, 12, No. 8-9, 663-687.

15. Haldor Topsøe A/S. Making 'natural' gas from coal. Chemical Engineering, 2007, 114, No. 2.

16. Arizona Public Service. Hydrogasification project aims to produce clean energy from coal, wind and biomass. Chemical Engineering, 2007, 114, No. 5.

17. Hofbauer H., Rauch R., Loeffler G., Kaiser S., Fercher E. and TRemmel H. Six years experience with the FICFBgasification process. 12th European Conference on Biomass for Energy, Industry and Climate Protection, Amsterdam, 2002.

18. Proll T., Aichernig C., Rauch R. and Hofbauer H. Fluidized bed steam gasification of solid biomass performance characteristics of an 8 MWth combined heat and power plant. International Journal of Chemical Reactor Engineering, 2007, 5, A54.

19. StÅHL K., WAldheim L., MorRis M., JohnsSOn U. and GÅRDMARK L. Biomass IGCC at Värnamo, Sweden - past and future. Proceedings of a GCEP Energy Workshop, 2004.

20. STÅHL K. The Värnamo Demonstration Plant - A Demonstration Plant for CHP Production, Based on Pressurized Gasification of Biomass. Demonstration Programme 1996-2000. European Commission, Swedish Energy Agency, Sydkraft AB, 2001.

21. Mozaffarian M., Zwart R. W. R., Boerrigter H. and DeURWAARDER E. P. Biomass and waste-related SNG production technologies: technical, economic and ecological feasibility. Proceedings of the 2 nd World Conference and Technology Exhibition on Biomass for Energy, Industry and Climate Protection, Rome, 2004.

22. van der Drift A., van der MeiJden C. M. and Boerrigter H. Milena gasification technology for high efficient SNG production from biomass. Proceedings of the 14th European Biomass Conference \& Exhibition, Paris, 2005.

23. ZWARt R. W. R., Boerrigter H., DeurWaARder E. P., VAN der Meijden C. M. and van PaAsen S. V. B. Production of Synthetic Natural Gas (SNG) from Biomass Development and Operation of an Integrated bio-SNG System. Energy Research Centre of the Netherlands, Petten, 2006, ECN-E-06-018.

24. Patel J. and Salo K. Carbona's long journey from pilot to demo plant. Modern Power Systems, 2004, June 25-27.

25. Patel J. The $5 \mathrm{MW}$ Skive, Denmark biomass gasificationgas engine (BGGE) demonstration project. Smallwood 2004: Creating Solutions for Using Small Trees, Sacramento, 2004.

26. Patel J. and Salo K. Demonstration of new gasification technology. Proceedings of the 2nd World Biomass
Conference, Biomass for Energy, Industry and Climate Protection, Rome, 2004.

27. Henriksen U., Ahrenfeldt J., Jensen T. K., Gøbel B., Bentzen J. D., Hindsgaul C. et al. The design, construction and operation of a $75 \mathrm{~kW}$ two-stage gasifier. Energy, 2006, 31, No. 10-11, 1542-1553.

28. RAdMANeSh R., CNAOUKI J. and GuY C. Biomass gasification in a bubbling fluidized bed reactor: experiments and modeling. AIChE Journal, 2006, 52, No. 12, 4258-4272.

29. Cao Y., Wang Y., Riley J. T. and Pan W.-P. A novel biomass air gasification process for producing tar-free higher heating value fuel gas. Fuel Processing Technology, 2006, 87, No. 4, 343-353.

30. BABU S. P. Perspectives on Biomass Gasification. International Energy Agency, Paris, 2006.

31. Hoffmann B. Process for the production of the synthetic biofuel 'SunDiesel'. Aufbereitungstechnik, 2008, 49, No. 1-2, 6-17.

32. Kandassamy K., Natarajan E. and Renganarayanan S. Comparative analysis of biomass gasifiers for thermal and power applications. Proceedings of an International Conference on Fluidized Bed Combustion. ASME, New York, 2003, 781-790.

33. BRidgWATER A. V. The technical and economic feasibility of biomass gasification for power generation. Fuel, 1995, 74, No. 5, 631-653.

34. Albertazzi S., Basile F., Brandin J., Einvall J., Hulteberg C., Fornasari G. et al. The technical feasibility of biomass gasification for hydrogen production. Catalysis Today, 2005, 106, No. 1-4, 297-300.

35. CHOREn. Press release 17/04/2008. See http:// www.choren.com/de/choren_industries/ informationen_presse/pressemitteilungen/?nid=184 for further details. Accessed 08/12/2008.

36. Seemann M., Biollaz S., Aichernig C., Rauch R., Hofbauer H. and Косн R. Methanation of bio-syngas in a bench scale reactor using a slip stream of the FICFB gasifier in Güssing. Proceedings of the 2nd World Conference on Biomass for Energy, Industry and Climate Protection, Rome, 2004, 1162-1164.

37. Bolhar-NordenKampF M. and Hofbauer H. Biomass gasification combined cycle thermodynamic optimisation using integrated drying. Proceedings of ASME Turbo Expo, Vienna, 2004, 7, 35-43.

38. Amos W. A. Report on Biomass Drying Technology. National Renewable Energy Laboratory, Colorado, 1998, NREL/TP-570-25885.

39. Brammer J. G. and Bridghater A. V. The influence of feedstock drying on the performance and economics of a biomass gasifier-engine CHP system. Biomass and Bioenergy, 2002, 22, No. 4, 271-281.

40. Cummer K. R. and Brown R. C. Ancillary equipment for biomass gasification. Biomass and Bioenergy, 2002, 23, No. 2, 113-128.

41. Hofbauer H. and Rauch R. Stoichiometric water consumption of steam gasification by the FICFBgasification process. In Progress in Thermochemical Biomass Conversion (BRIDGEWATER A. V. (ed.)). Blackwell, Oxford, 2001, 199-208.

42. SeEmann M. Methanation of Biosyngas in a Fluidized Bed Reactor. PhD thesis, Swiss Federal Institute of Technology, Zürich, 2006. 
43. Gil J., Corella J., Aznar M. P. and Caballero M. A. Biomass gasification in atmospheric and bubbling fluidized bed: effect of the type of gasifying agent on the product distribution. Biomass and Bioenergy, 1999, 17, No. 5, 389-403.

44. Milne T. A., Evans R. J. and Abatzoglou N. Biomass Gasifier 'Tars': Their Nature, Formation, and Conversion. National Renewable Energy Laboratory, Colorado, 1998, NREL/TP-570-25357.

45. Bergman P. C. A., van PaAsen S. V. B. and Boerrigter H. The novel 'OLGA' technology for complete tar removal from biomass producer gas. In Pyrolysis and Gasification of Biomass and Waste (Bridgewater A. V. (ed.)). CPL Press, Berks, 2003.

46. HAN J. and KIM H. The reduction and control technology of tar during biomass gasification/pyrolysis: an overview. Renewable and Sustainable Energy Reviews, 2008, 12, No. 2, 397-416.

47. Boerrigter H., van Paasen S. V. B., Bergman P. C. A., Könemann J. W., EMmen R. and Wijnands A. 'OLGA' Tar Removal Technology. Energy Research Centre of the Netherlands, Petten, 2005, ECN-C-05-009.

48. Pfeifer C., Rauch R. and Hofbauer H. In-bed catalytic tar reduction in a dual fluidized bed biomass steam gasifier. Industrial and Engineering Chemistry Research, 2004, 43, No. 7, 1634-1640.

49. Gallagher JR J. E. and EuKer JR C. A. Catalytic coal gasification for SNG manufacture. International Journal of Energy Research, 1980, 4, No. 2, 137-147.

50. Forzatti P. and Lietti L. Catalyst deactivation. Catalysis Today, 1999, 52, No. 2-3, 165-181.

51. Vogel A., Bolhàr-NordenKampF M., Kaltschmitt M. and HofBAUER H. (eds) Analyse und evaluierung der thermochemischen vergasung von biomasse. In Schriftenreihe Nachwachsende Rohstoffe, Band 29. FNR, Gülzow, 2006.

52. Bair W. G., LePpin D. and LeE A. L. Design and operation of catalytic methanation in hygas pilot plant. Advances in Chemistry Series, 1975, No. 146, 123-137.

53. Moeller F. W., Roberts H. and Britz B. Methanation of coal gas for SNG. Hydrocarbon Processing, 1974, 53, No. 4, 69-74.

54. Harms H. G., Hohlein B., Jorn E. and Skov A. High-temp methanation tests run. Oil and Gas Journal, 1980, 78, No. 15, 120-135.

55. Friedrichs G. and Wismann G. Untersuchung über die Einsatzmöglichkeiten gekühlter Gas/FeststoffDruckwirbelschichten, insbesondere der COMFLUXTechnik für chemische Prozesse (Investigation Concerning the Application of Cooled Gas/solid Pressurized Fluidized beds, in Particular the COMFLUX-Technique for Chemical Processes). Thyssengas GmbH, Duisburg, 1986, Contract No. 03-E-6383-A, pp. 9-33.

56. Seemann M. C., Schildhauer T. J., Biollaz S. M. A., STUCKI S. and WOKAUN A. The regenerative effect of catalyst fluidization under methanation conditions. Applied Catalysis A: General, 2006, 313, No. 1, 14-21.

57. HaSSAN S. M. N. Techno-Economic Study of $\mathrm{CO}_{2}$ Capture Process for Cement Plants. MSc thesis, University of Waterloo, 2005.

58. Hassan S. M. N., Douglas P. and Croiset E. Technoeconomic study of $\mathrm{CO}_{2}$ capture from an existing cement plant using MEA scrubbing. International Journal of Green Energy, 2007, 4, No. 2, 197-220.

59. Radgen P., Cremer C., Warkentin S., Gerling P., May F. and Knopf S. Verfahren zur $\mathrm{CO}_{2}$ - Abscheidung und Speicherung. Umweltbundesamt, Dessau, 2006, ISSN 1611-8855.

60. Abu-Zahra M. R. M., Schneiders L. H. J., Niederer J. P. M., Feron P. H. M. and Versteeg G. F. $\mathrm{CO}_{2}$ capture from power plants. Part I. A parametric study of the technical performance based on monoethanolamine. International Journal of Greenhouse Gas Control, 2007, 1, No. 1, 37-46.

61. Abu-Zahra M. R. M., Niederer J. P. M., Feron P. H. M. and Versteeg G. F. $\mathrm{CO}_{2}$ capture from power plants. Part II. A parametric study of the economical performance based on mono-ethanolamine. International Journal of Greenhouse Gas Control, 2007, 1, No. 2, 135-142.

62. Singh D., Croiset E., Douglas P. L. and Douglas M. A. Techno-economic study of $\mathrm{CO}_{2}$ capture from an existing coal-fired power plant: MEA scrubbing vs. $\mathrm{O}_{2} / \mathrm{CO}_{2}$ recycle combustion. Energy Conversion and Management, 2003, 44, No. 19, 3073-3091.

63. Alie C., Backham L., Croiset E. and Douglas P. L. Simulation of $\mathrm{CO}_{2}$ capture using MEA scrubbing: a flowsheet decomposition method. Energy Conversion and Management, 2005, 46, No. 3, 475-487.

64. European Association for the StrEAMLININg OF ENERgy EXCHANGE-GAS. Harmonisation of Natural Gas Quality. EASEE-gas, Paris, 2005, CBP 2005-001/01.

65. Linnhoff B., Townsend D. W., Boland D., Hewitt G. F., Thomas B. E. A., GuY A. R. et al. A User Guide on Process Integration for the Efficient Use of Energy. IChemE, Rugby, 1994.

66. LinNHOFF B. Pinch analysis - a state-of-the-art overview. Chemical Engineering Research and Design, 1993, 71, No. A5, 503-522.

67. CAnMet Energy Technology. Pinch Analysis for the Efficient Use of Energy, Water and Hydrogen. Natural Resources of Canada, Varennes, 2003.

68. Wising U. Process Integration in Model Kraft Pulp Mills: Technical, Economic and Environmental Implications. $\mathrm{PhD}$ thesis, Chalmers University of Technology, Gothenburg, 2003.

69. Gassner M. and Marechal F. Methodology for the optimal thermo-economic, multi-objective design of thermochemical fuel production from biomass. Computers and Chemical Engineering, 2009, 33, No. 3, 769-781.

70. Gassner M. and Marechal F. Thermo-economic optimisation of the integration of electrolysis in synthetic natural gas production from wood. Energy, 2008, 33, No. 2, 189-198.

71. Thunman H., Åmand L.-E., Leckner B. and Johnsson F. A cost effective concept for generation of heat, electricity and transport fuel from biomass in fluidised bed boilers using existing energy infrastructure. Proceedings of 15 th European Biomass Conference \&t Exhibition, Berlin, 2007.

72. Ådahl A., Harvey S. and Berntsson T. Assessing the value of pulp mill biomass savings in a climate change conscious economy. Energy Policy, 2006, 34, No. 15, 2330-2343. 
73. ÅDAhl A. and Harvey S. Energy efficiency investments in Kraft pulp mills given uncertain climate policy.

International Journal of Energy Research, 2007, 31, No. 5, 486-505.
74. Axelsson E., Harvey S. and Berntsson T. A tool for creating energy market scenarios for evaluation of investments in energy intensive industry. Energy, 2008, in press, DOI: 10.1016/j.energy.2008.08.017

\section{What do you think?}

To comment on this paper, please email up to 500 words to the editor at journals@ice.org.uk

Proceedings journals rely entirely on contributions sent in by civil engineers and related professionals, academics and students. Papers should be 2000-5000 words long, with adequate illustrations and references. Please visit www.thomastelford.com/journals for author guidelines and further details. 